\title{
Em processo: questões de uma investigação em/sobre deslocamentos
}

\author{
In progress: issues of an investigation in/on displacement
}

Aline Nunes

\begin{abstract}
Resumo
O texto que segue busca realizar conexões entre certos aspectos problematizados no decorrer do Colóquio Internacional de Educação e Visualidades, a partir das reflexões que emergem da investigação doutoral à qual me dedico. Procuro entrecruzar à temática do colóquio, "Incômodos", meus interesses de pesquisa, na medida em que explicito alguns dos percursos realizados até então: a perspectiva narrativa autobiográfica, como possibilidade metodológica; a cultura visual enquanto posicionamento epistemológico; e os deslocamentos enquanto temática que permeia toda a discussão proposta na investigação doutoral.
\end{abstract}

Palavras-chave: processo investigativo, deslocamentos, perspectiva narrativa autobiográfica, visualidades.

\begin{abstract}
The following text tries to make connections between certain aspects problematized during the International Conference on Education and Visualities, departing from the reflections that emerge from the doctoral research to which I dedicate myself. I seek to intersect the theme of the conference, "Disturbance", to my research interests, to the extent that I make explicit some of the journeys done so far: the autobiographical narrative perspective as methodological possibility; visual culture as epistemological positioning; and displacements as a theme that permeates all discussion on the proposed doctoral research.
\end{abstract}

Keywords: research process, displacements, autobiographical narrative perspective, visualities.

\section{Sobre incômodos}

A escrita do artigo em questão está pautada em alguns aspectos oriundos dos debates e problematizações mantidas durante o III Colóquio Internacional Educação e Visualidades: Incômodos. Certos temas abordados durante os dias do evento seguem ressoando nos meandros acadêmicos, entre professores e colegas pesquisadores, bem como no decurso da produção da tese doutoral que realizo atualmente ${ }^{1}$, o que também denota a permanência de certos incômodos e dúvidas, que mobilizam novas perguntas.

Neste sentido, focalizo tais reflexões conectando-as aos próprios embates que emergem do processo investigativo que ora desenvolvo, seja no que diz respeito aos modos com que vamos aprendendo a ser investigadores ou ainda, em torno aos interesses temáticos que envolvem este trabalho, a partir do compartilhamento dos caminhos que vão sendo escolhidos e da experiência vivenciada.

\footnotetext{
$1 \quad$ Tese doutoral produzida no Programa de Pós Graduação em Arte e Cultura Visual, da Faculdade de Artes Visual, Universidade Federal de Goiás. A investigação é orientada pela professora Doutora Alice Fátima Martins, e está inserida na Linha de Pesquisa Culturas da Imagem e Processos de Mediação. A pesquisa é integralmente financiada pela agência de fomento CAPES.
} 


\section{Uma investigação de dores e delícias e...}

Empreender um processo investigativo em nível doutoral poderia ser descrito com a conhecida canção de Caetano Veloso, Dom de Iludir, em que este fala sobre a dor e a delícia de ser o que é. $E$, ao citá-la não o faço no intuito de falar desde uma posição antagônica, binarista, de pensar que as coisas só podem ser opostas: boas ou ruins, prazerosas ou dolorosas, trágicas ou cômicas. Ao contrário, quisera centrar-me na conjunção " $e$ " que pode unir estas sensações, quase como se juntas fossem capazes de transformar-se em outra sensação. Dor e delícia, e também desconforto e entusiasmo e imersão e descobertas e tropeços e achados e... tantas coisas mais, variáveis, mas ainda assim misturadas e quase simultâneas.

Encontro-me no terceiro ano dedicado à realização da pesquisa de doutorado e, posso dizer que estas sensações díspares e por vezes até incômodas, próprias do caminho de produção e escrita da tese seguem comigo. Talvez isso tudo seja um indício do quanto aceitar o desafio de produzir uma pesquisa doutoral implica em vivê-la em tempo integral, mesmo quando pensamos estar distantes, ou dedicados a projetos paralelos. Lembro-me da autora Maria Ester de Freitas (2002) que em seu texto "Viver a tese é preciso" remete-se a este fato, em tom de brincadeira, mencionando que durante o período de produção da tese tudo parece conspirar para que o tema ao qual nos dedicamos seja colocado em destaque ou levado como se fosse o mais importante do universo. Ou seja, tudo acaba sendo relacional e levando-nos ao tema de nossas investigações, seja de modo mais ou menos direto.

Não por acaso o tema do simpósio, Incômodos, buscou justamente colocar em pauta de discussão os meandros daquilo que nos passa enquanto pesquisadores, ao largo dos processos de descobrir e escolher instrumentos, procedimentos, metodologias, ajustar perguntas e situá-las em nossos campos de estudo. Procurou ainda discutir como, em meio aquilo que nos parece caótico, aos poucos encontramos caminhos e linhas de fuga para seguir em nossos trabalhos.

Assim, à continuação escolho compartilhar parte dos percursos que me levaram a optar pela perspectiva metodológica com a qual venho operando na investigação doutoral, sinalizando ao longo do texto algumas das questões às quais me dedico neste trabalho.

\section{Uma via possível}

No decorrer do primeiro ano de doutorado, conforme esperado, o projeto com o qual iniciei o curso foi ganhando outros contornos. Aos poucos, foi dando espaço a distintas perguntas e, sobretudo, configurando um outro mapa, em conformidade com desejos e 
interesses teóricos que foram se atualizando. Inclusive um ajuste no sentido de acompanhar as linhas investigativas do Programa de Pós Graduação onde me inseri, tais como pensar uma proposta de pesquisa que estivesse mais em consonância com o campo da arte e da cultura visual, articulado à linha de "Culturas de imagem e processos de mediação".

Inicialmente o projeto esteve bastante focado no tema da docência e da formação inicial do professor em artes visuais (devido ao trabalho que realizo em cursos de licenciatura e também pelo fato de ter desenvolvido uma pesquisa de mestrado com este direcionamento, vinculada a um PPG em educação). Não obstante, na medida em que novas leituras foram feitas, a partir das sessões de orientação e do trabalho nas disciplinas, uma nova cartografia metodológica e conceitual foi se desenhando.

Assim que, ao atentar para estes deslocamentos, tanto de ordem geográfica (como a mudança de cidade e estado, para o ingresso no doutorado e todas as outras mudanças que este processo implica), quanto afetiva (novos projetos de vida, perspectivas e modos de se posicionar frente aos acontecimentos; o surgimento de novas relações; o encontro com outras referências e conceitos...), fui percebendo a presença de novas preocupações, que acabaram por afetar os interesses anteriores.

Os novos interesses foram percebidos e trabalhados através de um procedimento em especial: a escrita em diários. Este exercício, realizado cotidianamente, ajudou a situarme enquanto investigadora, a pontuar e discorrer sobre aspectos que emergiam naquele dado momento (o primeiro ano do curso).

Neste sentido, além de querer destacar o largo uso que faço deste tipo de escrita, no decurso de minha vida pessoal e acadêmica, ressalto também a importância dada a esta possibilidade metodológica, enquanto ainda era estudante do curso de licenciatura em artes visuais, da UFSM, ou mesmo, ao longo do mestrado em Educação, quando, por incentivo da professora Marilda Oliveira de Oliveira, os estudantes eram convidados a manter seus diários, como possibilidade de, a partir desta escrita, nutrir um processo de reflexão sobre a docência e sobre sua própria formação (pessoal e profissional) enquanto professores do campo das artes visuais. São muitos os textos de sua autoria, que problematizam a potencialidade deste tipo de escrita e de sua pertinência enquanto ela mesma parte agenciadora dos processos investigativos. Dentre eles destacaria alguns dos mais recentes (OLIVEIRA, 2013; 2012; 2011). 
Aos poucos, de dentro desta escrita nos diários ${ }^{2}$, fui tendo mais clareza sobre minha relação com o tema dos deslocamentos, a partir do deslocamento territorial que estava vivenciando. Os acontecimentos e fragmentos relatados no diário com frequência estavam conectados ao fato de estar em outro território, contavam sobre como é sentirse estrangeiro no próprio país, sobre rupturas necessárias para que algo novo possa ser começado e sobre negociar e inventar para si um lugar próprio, ainda que este se saiba provisório.

A princípio, produzi uma escrita bastante focada nas perguntas ${ }^{3}$ que, posteriormente foram propostas aos sujeitos que viriam a participar do trabalho. Sendo assim, os relatos produzidos no diário tinham como questões os investimentos feitos em nome destes trânsitos. Ainda, continham reflexões sobre os processos de adaptação, as descobertas e sobre a necessidade de rever formas instauradas de lidar com determinados conflitos, no intuito de seguir aprendendo desde outras tomadas de posição.

Neste exercício constante de se ver, a partir do que foi escrito, busco em Larrosa (2006, p.7) uma reflexão acerca de tal processo:

Talvez (...) não sejamos outra coisa que não um modo particular de contarmos o que somos. E, para isso para contarmos o que somos talvez não tenhamos outra possibilidade senão percorrermos de novo as ruínas de nossa biblioteca, para aí tentar recolher as palavras que falem por nós (...) Não será talvez a forma sempre provisória e a ponto de desmoronar que damos ao trabalho infinito de distrair, de consolar ou de acalmar com histórias pessoais aquilo que nos inquieta?

Vejo que a escrita do diário permite exatamente perceber esta qualidade de desmoronamento e provisoriedade expressa através do que é relatado. O estado das coisas se modifica conforme a sucessão dos acontecimentos e o agenciamento de novas intensidades. A leitura de um livro escolhido ao acaso, um filme que nos afeta, uma música que se ouve pela primeira vez, a descoberta de uma rua em meio aos percursos realizados cotidianamente ou quando se está à deriva. Tudo isto é marcante, mas está também prestes a se desfazer, gerando novas relações e tornando-se uma outra experiência.

\footnotetext{
2 Sobre o diário como procedimento nos processos de pesquisa, discuto mais especificamente em textos publicados anteriormente: Nunes (2012); Nunes (2012 a)

As perguntas iniciais foram: Como se deu esta(s) viagem(s)? O que é produzido e/ou construído subjetivamente neste processo de deslocar-se? Que experimentações e investimentos são realizados neste processo? A partir de cada retorno, outros questionamentos foram enviados, no intuito de desenvolver e aprofundar certos aspectos mencionados nos relatos. As primeiras entrevistas foram realizadas através de email, no período de julho e outubro de 2012.
} 
No intuito de ampliar as reflexões sobre os deslocamentos e sobre o que implica encontrar-se nesta condição movediça, nasceu o objetivo de trocar e conhecer, desde relatos e perspectivas diferentes, o que passa quando outras pessoas também se colocam neste processo. Buscar conhecer o que muda, o que é mobilizado e fabricado a partir destes trânsitos geográficos e, sobretudo destes trânsitos subjetivos.

Como, ao sair de um território (e aqui não me refiro somente ao território geográfico), vamos forjando outros modos de vida em meio ao que nos parece desconhecido? Ainda: como forjar novos modos de se estar, para ser capaz de fazer diferentemente daquilo a que se está tão acostumado?

Conforme Preciosa (2010, p.52) é preciso "ser arrojado para se querer tornar em tudo o que não se é. É preciso o esforço da torção para chegar a desconjuntar o sujeito que se é, que se acostumou a ser". Para tanto, é sobre este esforço da torção que direciono meus interesses nesta investigação, enquanto possibilidade de problematizar aquilo que nos passa durante o processo de estar em deslocamento.

Para isso vejo no conceito de desterritorialização, de Deleuze e Guattari (1995) uma ferramenta com a qual operar naquilo que é desfeito, dilacerado neste contexto cambiante pelo qual interesso-me. O conceito é utilizado para pensar sobre o processo de deixar um território (que não é necessariamente físico), com domínios e pertencimentos demarcados em busca de criar outras conexões, outros agenciamentos, onde seja possível rever crenças, certezas e aquilo que tomamos como verdade e já sabido. Experimentar um estado de desaprender, desconstruir-se e questionar-se para seguir aprendendo.

Assim, "território são as propriedades (...) e sair do território é se aventurar. O território só vale em relação a um movimento do qual se sai dele" (DELEUZE, 1988, p.4), e desterritorializar-se pressupõe uma reterritorialização, que inclui pensar o mundo e a si próprio desde uma outra postura, que busca uma experimentação.

A reterritorialização compreende um reposicionamento, ainda que provisório e instável: implica novas aprendizagens em outras relações. Sair de um território, deixar o que antes era seguro e familiar (espaços, lugares, crenças, situações e pessoas) coloca-nos em perspectiva, nos tira o que antes era uma quase certeza, e nos obriga a ver com nosso "olho vibrátil" (ROLNIK, 1997, p.1), isto é, uma potencialidade do olho que não mais o deixa ver de modo desatento, mas que o faz ser tocado pela força daquilo que vê. 
Ao caminhar em busca de uma investigação onde o mais importante talvez surgisse daquilo que é da ordem do cotidiano e particular, e que fosse produzida a partir dos relatos de acontecimentos menores, pequenos feitos e experiências singulares, vi no uso da perspectiva narrativa de cunho autobiográfico potência para dar prosseguimento ao trabalho. Considero que tal abordagem atua na pesquisa como um meio de conhecer como os sujeitos (que dela participam) se reinventam, se modelam, se desconstroem e elaboram para si outros mundos a partir deste deslocamento.

Atualmente, conto com a participação de seis estudantes de pós-graduação (em nível de mestrado e doutorado), oriundos de diferentes lugares do Brasil e vinculados a duas instituições de ensino superior. O convite foi realizado tomando como ponto de partida minha experiência de deslocamento, estendendo o convite a pessoas que, em diferentes momentos tiveram seus caminhos entrecruzados aos meus, seja por vias profissionais ou pessoais e que se colocaram em trânsito em busca de uma formação continuada, através do trabalho como investigadores.

A abordagem da experiência, neste caso, pode ser entendida como algo potente no campo da investigação acadêmica e como uma forma de ampliar os caminhos de se compreender e ver com múltiplas lentes os fatores de construção do social e cultural dos quais somos partícipes. Problematizar a experiência possibilita por tanto, uma outra forma de vivê-la e de experimentá-la, segundo as ressonâncias daquilo que é conhecido por meio dos relatos do outro.

Ao trabalhar com a narrativa de cunho autobiográfico é importante não perder de vista que esta não é uma narração celebratória do eu, mas sim "un camino para establecer relaciones, desvelar vínculos y realizar aportaciones al campo de estudio que nos hemos propuesto recorrer" (HERNÁNDEZ e RIFÁ, 2011, p.15). Quando nos dispomos a pensar, a escrever sobre o que nos passa não é necessário que se conte uma história com início, meio e fim, conforme tenha sido. No momento que contamos, novos detalhes nos surpreendem, outros aspectos ganham maior relevância... Por vezes narramos conforme gostaríamos que tivesse sido e não exatamente como ocorreu.

Não obstante, o ato de criar, de invencionar sobre aquilo que é sentido, forjar a criação de outros encaminhamentos a partir de dado acontecimento é também o que nos interessa em um relato produzido e que pode ser objeto em uma investigação narrativa de cunho autobiográfico. Esta capacidade de se produzir outros encaminhamentos, outras relações e verdades sobre um determinado fato vivido é uma forma de compreender como somos subjetivados por nossas experiências. 
A perspectiva narrativa autobiográfica, tal como a concebo, tem me permitido explorar mais abertamente os procedimentos metodológicos, uma vez que para obter relatos, é possível fazer uso não só de imagens e da produção de textos, mas da combinação com textos literários, músicas, narrativas fílmicas, produções artísticas, dentre muitos outros elementos que podem vir a contribuir na elaboração de uma cartografia autobiográfica, que problematiza os câmbios subjetivos dos sujeitos que nela estão implicados.

Estabelecer conexões, criar pontes entre os múltiplos relatos e mapas produzidos por cada um dos sujeitos com os quais dialogo neste momento e ainda, entrecruzar suas histórias às minhas vem sendo um dos desafios do trabalho neste momento em que me encontro. Busco os aspectos recorrentes em suas escritas, procuro naquilo que não está explícito os silêncios, as nuances, as sutilezas contidas em seus relatos, acerca daquilo que thes passa durante este percurso incerto. São necessários repetidos adentramentos naquilo que foi cedido por cada participante, cada relato produzido contém em si muitas vias de entrada, e por esta razão vejo tais relatos como mapas abertos à experimentação, não só minha como daqueles que com eles venham a relacionar-se.

Talvez, um dos modos de adentrar e ver estes mapas/relatos seja por meio do diálogo com visualidades, por entender que neste exercício é possível complexizar o que já está contido na escrita. Além de escrever sobre a experiência de estar em deslocamento e o que ela agencia, sair à cata de imagens e buscar paisagens e momentos através de fotografias, ou de imagens oriundas de produções artísticas ou fragmentos de filmes, acabam por criar uma outra dimensão dentro dos processos de produzir uma narrativa. Lembrando que neste caso as imagens estão no trabalho como um modo a mais de contar ou de fazer emergir aspectos da experiência que se manteriam invisibilizados ou percebidos desde um outro prisma caso não fossem acrescidas a estas reflexões.

Ao realizar a investigação por esta via, situo-a no viés da cultura visual que considera que a potência das relações construídas não está propriamente nas imagens que se utiliza para estudar, mas sim naquilo que podemos fazer com elas e não sobre elas. Neste caso, as imagens "não remetem ao texto, mas antes constituem um relato autônomo que permite ao visualizador estabelecer outras pontes, nexos e interpretações. O texto, por sua vez, não fala sobre as imagens, mas a partir delas" (HERNÁNDEZ, 2013, p. 86).

Interessa-me por assim dizer, lançar imagens a partir das quais possa pensar nos deslocamentos longe das definições da palavra (ainda que esta possibilite aberturas múltiplas). Ao selecionar algumas imagens para compor esta cartografia ao longo do 
processo de investigação, estou certa de que ao retornar a determinados elementos cartografados (imagens e fragmentos de escrita) as impressões e motivos que me levaram a selecioná-los já serão distintos, já terão sido refeitos pelo tempo passado e pelas outras experiências que acabam por se justapor.

Assim, esta condição de mobilidade e de efemeridade permitidas pela articulação de imagens aos relatos escritos, de certo modo conferem o sentido do que acredito ser este processo de estar em deslocamento: uma condição onde os interesses, desejos e os estados facilmente se transformam, se rompem, desmoronam, mas sempre deixam pistas para que novas coisas sejam pensadas ou produzidas a partir destes escombros. Talvez, não por acaso, tenha percebido isso justamente ao notar a recorrência de imagens de ruínas, marcas e vestígios de antigas construções que foram aos poucos ganhando espaço nos relatos visuais que vinha produzindo para a pesquisa.

Abaixo, seleciono algumas das visualidades que foram incorporadas ao trabalho mais recentemente ${ }^{4}$ :

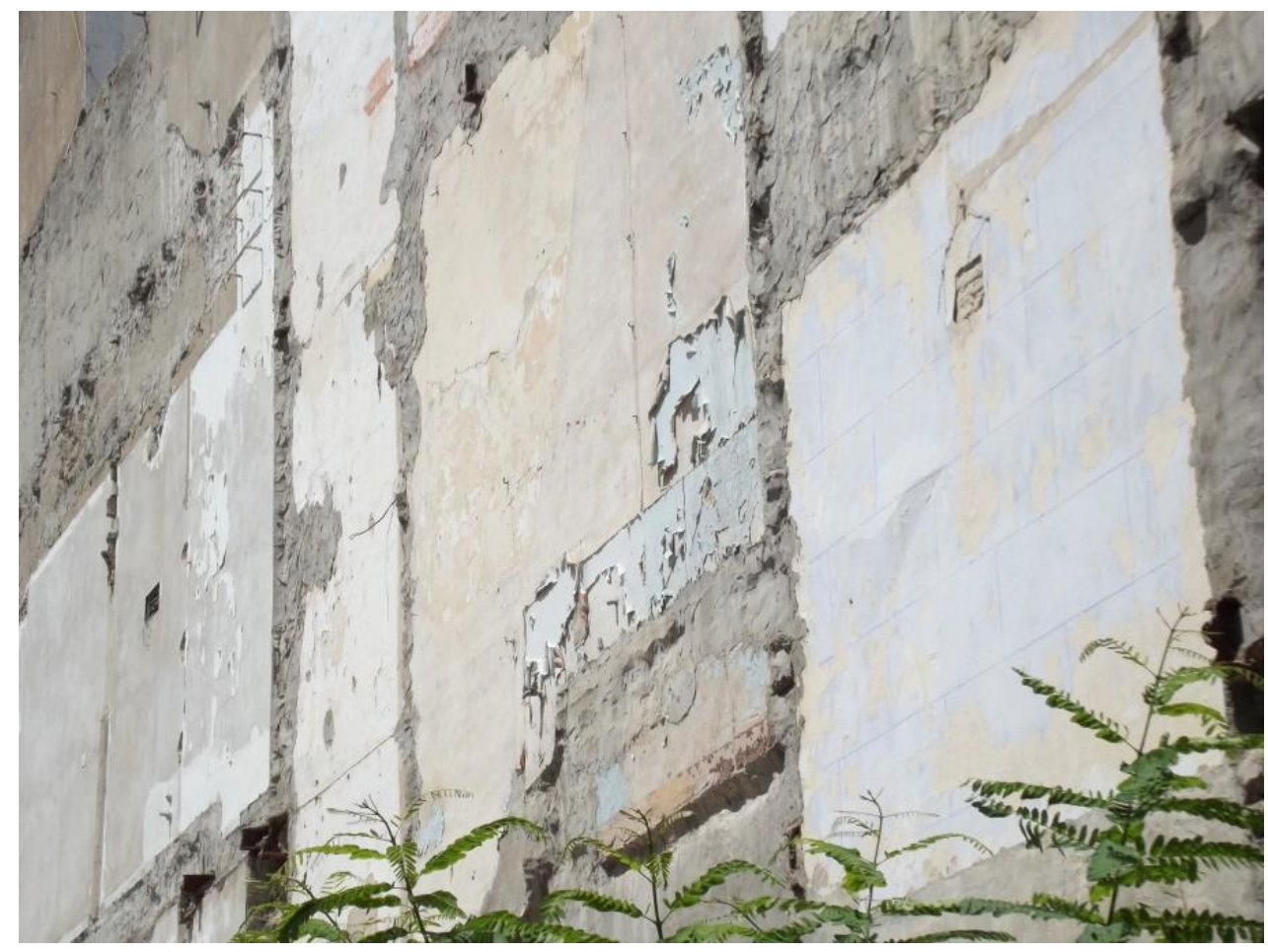

Fig. 01- vestígios de Triana, Sevilla. Arquivo pessoal da pesquisadora (2013)

A partir dos trânsitos que realizo durante o estágio de doutorado sanduíche, como parte do Programa de Bolsas de Doutorado Sanduíche no Exterior- PDSE (ofertado pela agência de fomento CAPES), vinculada à Universidade de Barcelona (UB), no Programa de Doctorado de Artes y Educación, sob orientação do professor Dr. Fernando Hernández. Assim, entre os meses de fevereiro de 2013 a janeiro de 2014 dedico-me a realizar parte da pesquisa teórica e de campo em Barcelona, bem como a participar de disciplinas e seminários na referida instituição. 


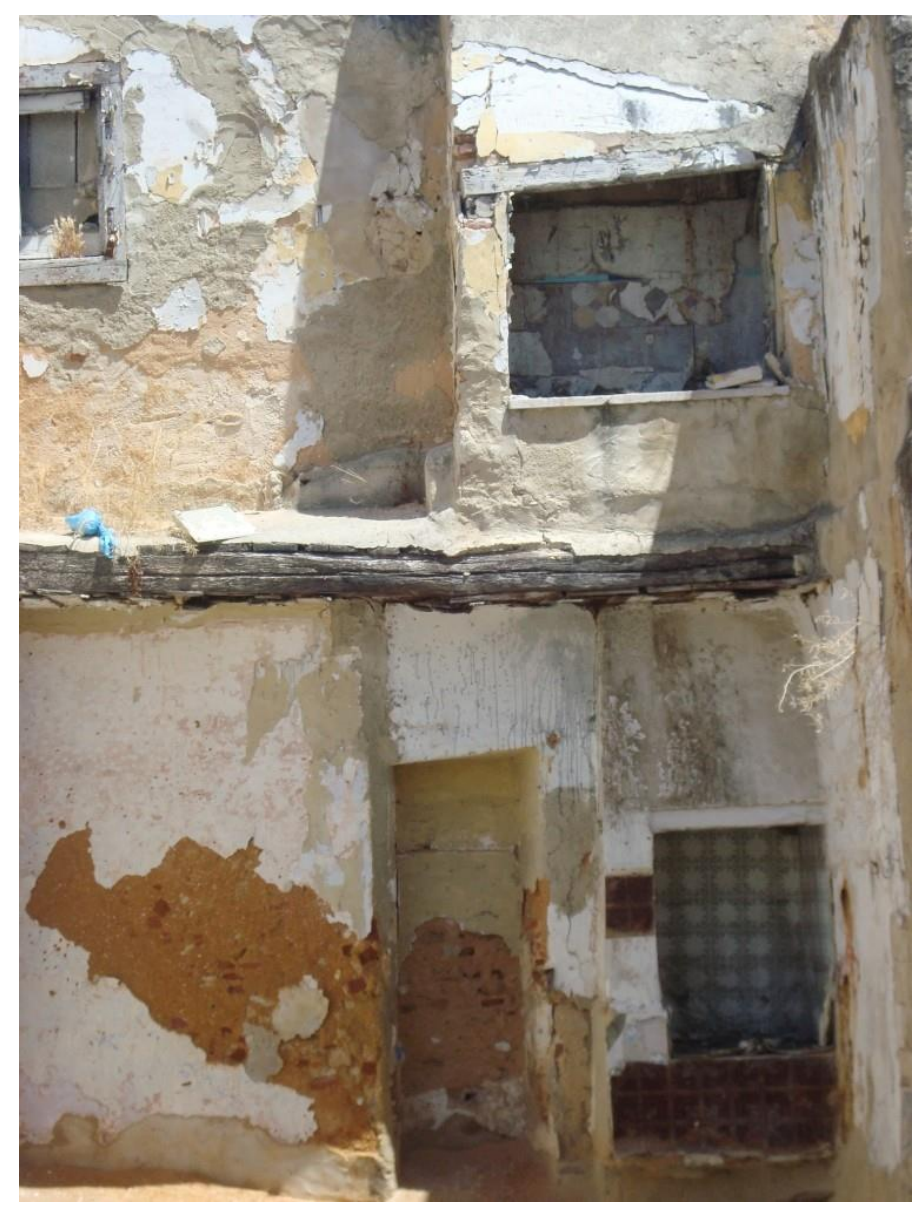

Fig. 02 - Casa em Lisboa. Arquivo pessoal da pesquisadora (2013)

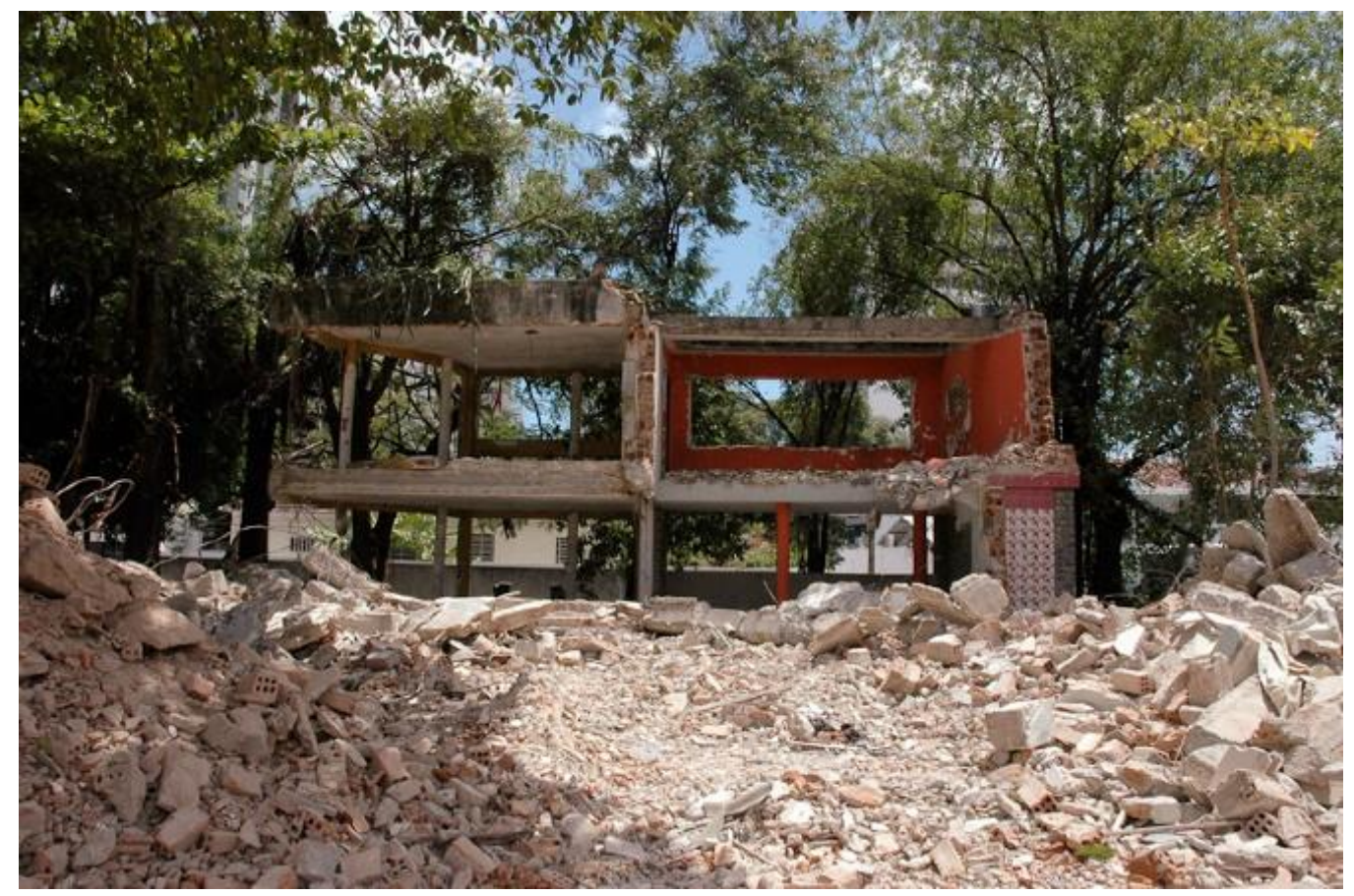

Figura 03- Série "Abertura de uma casa", do artista Jonathas Andrade. Disponível em: http://cargocollective.com/jonathasdeandrade/abertura-de-uma-casa 


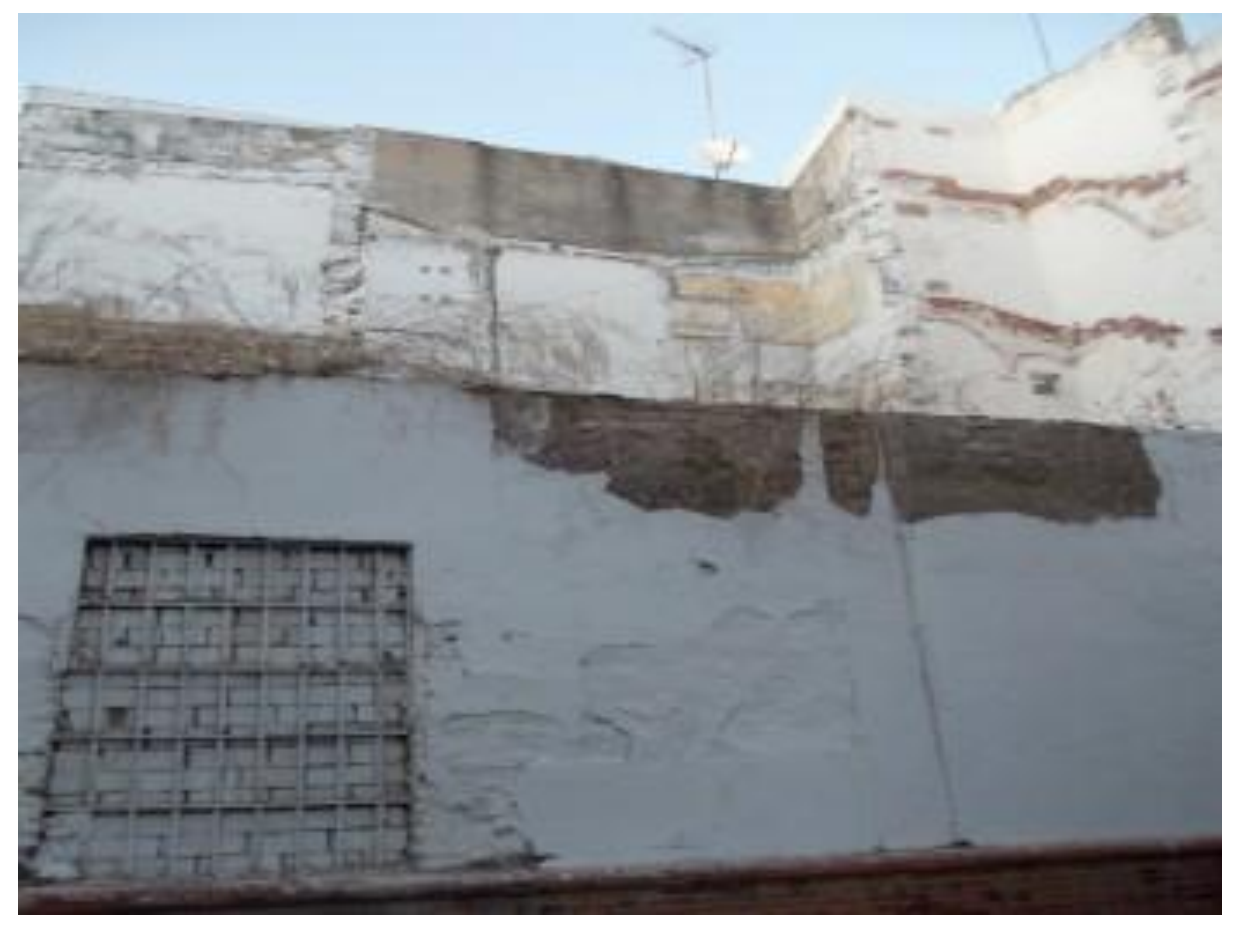

Fig. 04- Paredes em Sevilla. Arquivo pessoal da pesquisadora (2013)

Amparada pela cultura visual, assumo frente a este trabalho uma postura que entende

que o/a pesquisador(a) não aborda imagens e artefatos

visuais de

forma isolada, mas em relação aos relatos e discursos que medeiam a narrativa visual e em relação a outras imagens que conversam com, repudiam e/ou indagam as que escolhemos, ou seja, não há uma direção correta, única, a qual $o(a)$ pesquisador(a) deve se alinhar. Olhar para vários lados, em várias direções e planos, em tempos e fluxos diversos, é uma atitude que capacita o(a) pesquisador(a) a exercer sua tarefa de investigar. (MARTINS e TOURINHO, 2013, p. 67)

Portanto, posso dizer que frente a uma pesquisa ainda em processo, trago muito mais perguntas do que propriamente lanço respostas. Ao tentar promover esta articulação entre os meus escritos e imagens aos relatos partilhados por outros sujeitos com quem estabeleço esta conversação, adoto esta condição de quem trabalha experimentando e descobrindo possibilidades de produzir uma narrativa no meio do caminho explorado.

Os procedimentos destacados ao longo do texto, longe de serem vistos como caminhos exclusivos para se chegar até aqui, são pensados como possibilidades que servem para ampliar e deixar em aberto as formas de vermos e experimentarmos os deslocamentos sobre os quais me debruço. 
Mais do que falar de viagens, de mudanças geográficas, cidades ou países, a pesquisa tem por objetivo pensar sobre aquilo que é deslocado em nós, e que pode se dar a partir de diferentes dispositivos. No caso desta investigação o dispositivo que utilizo como recorte trata-se de um deslocamento territorial. Considerando que o que nos força a mudar, ou a pensar diferentemente daquilo que se pensa é

o mal-estar que nos invade quando forças do ambiente em que vivemos e que são a própria consistência de nossa subjetividade, formam novas combinações, promovendo diferenças de estado sensível em relação aos estados que conhecíamos e nos quais nos situávamos. Nestes momentos é como se estivéssemos fora de foco e reconquistar um foco, exige de nós o esforço de constituir uma nova figura. É aqui que entra o trabalho do pensamento: com ele fazemos a travessia destes estados sensíveis que embora reais são invisíveis e indizíveis, para o visível e o dizível. O pensamento, neste sentido, está a serviço da vida em sua potência criadora. (ROLNIK, 1995, p.1)

Trabalhar desde esta perspectiva não se configura como algo simples. Fazer esta travessia de estados sensíveis indizíveis, para o visível e dizível, sobretudo num processo investigativo que envolve o trabalho com relatos tão singulares, é de fato algo que pode assustar. Assumir esta posição implica tomar um cuidado no que diz respeito aos relatos cedidos, ao trato com os colaboradores e ainda, uma atenção redobrada aos limites daquilo que é demasiado particular, a ponto de não ser pertinente quando se trata de uma investigação. Por outro lado, aceitar este risco é também uma forma de contraporse àquilo que já está instituído e formatado enquanto interesse acadêmico, legitimado pelos grandes discursos das universidades.

\section{O que pode ser dito até aqui}

Mesmo com o propósito de discutir questões mais pontuais, a partir dos debates iniciados durante o referido Colóquio, é quase impossível manter-me em linha reta, sem desviar de alguns temas, ou mesmo, sem sentir necessidade de puxar muitos outros para serem acrescidos nesta reflexão que intentei promover.

Creio que falar dos percursos que criamos ao longo da realização de nossas investigações sempre nos leva a rever o que foi realizado até então, porém, sempre contando esta história de modo distinto: seja por escolher outras vias por onde começar, seja por criar alguns desvios no meio desta narração e levá-la para outros cantos. Ou seja, esta é uma cartografia viva, em constante movimento, não há como resistir a isso.

Mais interessante ainda é pensar que este texto, quando chegar a ser lido por outras pessoas, já estará repleto de equívocos, mudanças e eu estarei provavelmente 
pensando: poderia ter contado tudo isto de um modo muito diferente. O que me resta é ser paciente e saber que isso é parte do incômodo de quem não para, de quem segue buscando outras rotas possíveis, abrindo novos espaços para conseguir pensar e fazer algo através do qual ainda possa ser surpreendido.

Insisto ainda em dizer que este exercício de escrita, para um artigo que não será a tese, mas que trata de suas questões, é uma forma de mapear e ver o processo que está sendo construído, de ajustar perguntas, realizar outras conexões com nossos conceitos, categorias, porções de teoria... É criar uma possibilidade de compreender mais amplamente e explicitar, por meio do texto, aquilo que tanto se busca enquanto realizamos nossas investigações.

Por fim, havemos de lembrar que

não há um caminho traçado de antemão que bastasse segui-lo, sem desviar-se, para se chegar a ser o que se é. O itinerário que leve a um "si mesmo" está para ser inventado, de uma maneira sempre singular, e não se pode evitar nem as incertezas nem os desvios sinuosos. (LARROSA, 2006, p.9)

O encontro com este "si mesmo" pode acontecer de inúmeros modos, tantos quantos são os modos de experimentarmos sobre nós mesmos. Mas para isso, é preciso uma disposição para promover este encontro, é preciso colocar-se a criar este eu. E neste caso, já sabemos, não há caminho preciso, tampouco que possa ser tomado como receita a partir da trilha feita pelo outro.

\section{Referências}

ANDRADE, Jonathas. Abertura de uma casa. Disponível em: http://cargocollective.com/jonathasdeandrade/abertura-de-uma-casa. Acesso em: 1 de agosto de 2013.

DELEUZE, Gilles. O abecedário de Gilles Deleuze: transcrição integral do vídeo, para fins exclusivamente didáticos. Éditions Montparnasse: Paris, 1988.

DeleuZE, Gilles; GuATtARI, Felix. Mil Platôs: capitalismo e esquizofrenia. Vol.1. São Paulo: Editora 34, 1995.

FREITAS, Maria Ester de. Viver a tese é preciso! In: BIANCHETTI, Lucídio; MACHADO, Ana Maria Netto (orgs). A Bússola do escrever: desafios e estratégias na organização de teses e dissertações. Florianópolis/ São Paulo: Editora da UFSC/ Cortez Editora, 2002.

HERNÁNDEZ, Fernando. Pesquisar com imagens, pesquisar sobre imagens: revelar aquilo que permanece invisível nas pedagogias da cultura visual. In: MARTINS, Raimundo; 
TOURINHO, Irene (orgs.). Processos e práticas de pesquisa em cultura visual e educação. Santa Maria: Editora da UFSM, 2013, p. 77- 96.

HERNÁNDEZ, Fernando; RIFÀ, Montserrat. Investigación autobiográfica y cambio social. Barcelona, Octaedro, 2011.

LARROSA, Jorge. Pedagogia profana: danças, piruetas e mascaradas. Belo Horizonte: Editora Autêntica, 2006.

MARTINS, Raimundo; TOURINHO, Irene. Reflexividade e pesquisa empírica nos infiltráveis caminhos da Cultura Visual. In: MARTINS, Raimundo; TOURINHO, Irene (orgs.). Processos e práticas de pesquisa em cultura visual e educação. Santa Maria: Editora da UFSM. 2013, p. 61-76.

NUNES, Aline. Em deslocamento: possíveis trânsitos entre um diário de pesquisa e os diários de campo etnográfico. Revista INVISIBILIDADES, número 3. Setembro de 2012. p. 81-90. Disponível em: http://issuu.com/invisibilidades/docs/invisibilidades_03 Acesso em: 1 de agosto de 2013.

NUNES, Aline. Sobre a experiência de narrar e investigar autobiograficamente. Anais do $21^{\circ}$ Encontro Nacional de Pesquisadores em Artes Plásticas- ANPAP. 2012 a. Disponível em: http://www.anpap.org.br/anais/2012/pdf/simposio12/aline_nunes_da_rosa.pdf Acesso em: 1 de agosto de 2013.

OLIVEIRA, Marilda Oliveira de. O que pode um diário de aula? In: MARTINS, Raimundo; TOURINHO, Irene (orgs.). Processos e práticas de pesquisa em cultura visual e educação. Santa Maria: Editora da UFSM, 2013, p. 225-236.

OLIVEIRA, Marilda Oliveira de. Por uma abordagem narrativa e autobiográfica: diários de aula como foco de investigacão. In: MARTINS, R.; TOURINHO, (Org.). Educação da cultura visual: conceitos e contextos. Santa Maria: Editora da UFSM, 2011. p. 175-190.

OLIVEIRA, Marilda Oliveira de. Sobre os diários de aula no projeto PIBID artes visuais. Anais do $21^{\circ}$ Encontro Nacional de Pesquisadores em Artes Plásticas- ANPAP. 2012. Disponível em: http://www.anpap.org.br/anais/2012/pdf/simposio12/marilda_oliveira.pdf Acesso em: 1 de agosto de 2013.

PRECIOSA, Rosane. Rumores discretos da subjetividade: sujeito e escritura em processo. Porto Alegre: Sulina: Editora da UFRGS, 2010.

ROLNIK, Suely. Uma insólita viagem à subjetividade: fronteiras com a ética e a cultura. 1997, pp 1-11. Disponível em http://www.pucsp.br/nucleodesubjetividade/Textos/SUELY/viagemsubjetic.pdf Acesso em: julho de 2012.

ROLNIK, Suely. Ninguém é deleuziano. 1995. Disponível em http://www.pucsp.br/nucleodesubjetividade/Textos/SUELY/ninguem.pdf Acesso em: julho de 2012. 
VELOSO, Caetano. Dom de Iludir. Disponível em: http://letras.mus.br/caetanoveloso/44719/ Acesso em: 1 de agosto de 2013.

' Doutoranda do Curso de Pós-Graduação em Arte e Cultura Visual, Universidade Federal de Goiás. Bolsista Capes. ameline.nr@gmail.com

Recebido em: 23/09/2013

Aprovado em: 15/10/2013 